\title{
PENGARUH SENAM AEROBIK LOW IMPACT TERHADAP PENURUNAN NYERI PADA DISMINORE PRIMER REMAJA PUTRI DI SURAKARTA
}

\author{
Mellia Silvy Irdianty ${ }^{1}$ Fakhrudin Nasrul Sani ${ }^{2}$ Heni Nur Kusumawati ${ }^{3}$ \\ ${ }^{1}$ Prodi D-III Keperawatan STIKes Kusuma Husada Surakarta \\ ${ }^{2}$ Prodi D-III Keperawatan STIKes Kusuma Husada Surakarta \\ ${ }^{3}$ Prodi DIV Akupuntur Poltekkes Kemenkes Surakarta \\ ${ }^{1}$ silvy.irdianty@gmail.com fakhrudin_ns@ymail.com 2heninurkusumawati@yahoo.com
}

\begin{abstract}
Abstrak
Latar belakang: Ketidasiapan secara fisik dan psikologis terkadang menyebabkan remaja mengalami gangguan pada menstruasinya, diantaranya adalah nyeri haid atau sering disebut dismenorea. Nyeri yang dialami seringkali menganggu kegiatan sehari - hari bahkan remaja seringkali harus melewatkan pembelajaran di sekolah dikarenakan nyeri tersebut. Salah satu upaya non farmakologis yang dapat dilakukan untuk bisa mengurangi nyeri, salah satunya menggunakan senam aerobic low impact yang dilakukan 1 minggu sebelum menstruasi berlangsung. Tujuan: Mengetahui pengaruh senam aerobik low impact terhadap penurunan nyeri haid pada remaja putri yang mengalami disminore primer. Metode penelitian menggunakan rancangan prepost test without control yang dilakukan dengan melakukan suatu intervensi pada satu kelompok tanpa pembanding. Penelitian dilaksanakan di wilayah Surakarta dengan 30 responden remaja usia $12-15$ tahun. Analisis yang digunakan adalah wilcoxon test dengan tingkat kemaknaan 95\%. Hasil dari penelitian didapatkan ada pengaruh senam aerobic low impact terhadap penurunan skala nyeri haid pada remaja putri di Surakarta. Kesimpulan: Senam aerobic low impact terbukti memiliki pengaruh efektif dalam menurunkan derajat nyeri pada dismenore. Mayoritas responden yang sebelumnya mengalami nyeri sedang, menurun menjadi skla nyeri ringan.
\end{abstract}

Kata Kunci : Dismenore, Senam Aerobic Low Impact, Stretching, remaja putri.

\begin{abstract}
Background: Physical and psychological oxidation sometimes causes adolescents to experience menstrual disorders, including menstrual pain or often called dysmenorrhoea. Pain that is experienced often interferes with daily activities and even teenagers often have to skip learning at school because of the pain. One of the non-pharmacological efforts that can be done to reduce pain, one of which uses low impact aerobic exercise which is done 1 week before menstruation takes place. Objective: To determine the effect of low impact aerobic exercise on the reduction of menstrual pain in adolescent girls who experience primary disminore. The research method uses a pre-post test without control design which is done by conducting an intervention in one group without comparison. The study was conducted in the Surakarta region with 30 teenage respondents aged 12-15 years. The analysis used was Wilcoxon test with a significance level of $95 \%$. The results of the study found that there was an effect of low impact aerobic exercise on the reduction of menstrual pain scale in young women in Surakarta. Conclusion: Low impact aerobic exercise has been proven to have an effective effect on reducing the degree of pain in dysmenorrhea. The majority of respondents who previously experienced moderate pain, decreased to mild pain.
\end{abstract}

Keywords: Dysmenorrhea, Aerobic Low Impact Gymnastics, adolescent. 


\section{PENDAHULUAN}

Menstruasi merupakan salah satu tanda gejala pubertas yang dialami oleh remaja. Adanya perbaikan asupan nutrisi di masa sekarang, mengakibatkan banyaknya menstruasi terjadi pada anak yang baru memasuki masa remaja. Pubertas yang dialami oleh remaja secara dini seringkali mengakibatkan ketidaksiapan secara fisik dan psikologis, sehingga menstruasi pertama seringkali mengalami sebuah gangguan rasa nyaman seperti nyeri..

Nyeri haid atau seringkali disebut Dismenorea, seringkali dialami oleh remaja. Nyeri ini berada di skala sedang sampai berat tergantung pada pengalaman nyeri setiap individu. Manifestasi klinis pada disminore seringkali dijumpai seperti nyeri pada perut bawah seperti kram perut dan nyeri bagian pinggang yang menjalar sampai ke paha dan punggung. Disminore terbagi menjadi 2, yaitu disminor primer dan disminore sekunder.

Dismenorea primer seringkali disebut dengan disminore tanpa adanya penyebab dan murni dikarenakan status hormonal. Biasanya, disminor primer ini dialami oleh remaja pada awal masa menstruasi. Keparahan nyeri disminore seringkali disebabkan karena adanya obesitas, stress, dan kurangnya aktifitas fisik yang dilakukan. ${ }^{1}$ Hal ini tentu sangat berpengaruh terhadap kegiatan sehari - hari, remaja seringkali dijumpai tidak bisa masuk sekolah dikarenakan disminore primer ini. Nyeri hebat yang dialami oleh remaja memerlukan tindakan baik secara farmakologis maupun non farmakologis untuk bisa mengurangi gangguan rasa nyaman ini. ${ }^{2}$

Mayoritas wanita mengalami disminor primer, yang dapat menganggu aktivitas sehari hari ${ }^{3}$. Fenomena disminore remaja ini tidak hanya dialami di Indonesia tetapi juga di Negara yang lain. Seperti halnya penelitian yang dilakukan oleh French membuktikan bahwa prevalensi dismenorea meningkat pada gadis remaja, dengan prevalensi sekitar 20-90\%. Sedangkan, sekitar 15\% gadis remaja di Amerika Serikat mengalami dismenorea berat dan menjadi penyebab remaja tersebut tidak masuk ke sekolah. ${ }^{6}$

Sebuah penelitian secara kohort pada responden wanita Swedia menunjukkan bahwa prevalensi dismenorea tertinggi pada remaja usia 19 tahun adalah $90 \%$ dan $67 \%$ pada wanita usia 24 tahun. $10 \%$ dari wanita usia 24 tahun dengan adanya nyeri yang mengganggu kegiatan seharihari ${ }^{4}$.

Data di Indonesia sampai saat ini belum diketahui. Hasil penelitian tahun 2012 di 4 SLTP di Jakarta (733 subyek) sekitar $74,1 \%$ siswi mengalami dismenorea ringan sampai berat. Studi pendahuluan mengenai dismenorea yang dilakukan oleh Kurniawati and Kusumawati di SMK I Batik Surakarta mendapatkan bahwa siswa perempuan di sekolah tersebut pernah mengalami dismenorea dan terkadang meminta izin untuk pulang dikarenakan tidak tahan terhadap dismenorea yang mereka rasakan. Hasil penelitian tersebut menjelaskan bahwa sebanyak $52 \%$ pelajar di Surakarta tidak dapat melakukan aktivitas harian dengan baik dikarenakan dismenorea ${ }^{5}$.

Salah satu tindakan non farmakologis yang dapat dilakukan untuk mengatasi nyeri pada disminore adalah meakukan aktifitas kebugaran, yaitu senam aerobic low impact. Tindakannon farmakolis dilakukan sebagai pelengkap untuk meminimalisir tindakan farmakologis. Senam aerobik yang dilakukan berupa gerakan- gerakan dengan intensitas gerakan yang ringan atau lambat. Gerakan senam aerobic low impact terbukti dapat menjadi sebuah relaksasi dan distraksi tersendiri dalam menurunkan nyeri pada disminore remaja. ${ }^{11}$

Berdasarkan latar belakang tersebut, maka peneliti tertarik untuk melakukan penelitian dengan judul "Pengaruh Senam Aerobik Low Impact Terhadap Penurunan Nyeri Pada Disminore Primer Remaja Putri Di Surakarta".

\section{METODE}

Penelitian ini merupakan penelitian quasi experiment dengan rancangan pre-post testwithout control yang dilakukan dengan melakukan suatu intervensi pada satu kelompok tanpa pembanding. Penelitian dilaksanakan di wilayah Surakarta dengan 30 responden remaja usia 12- 15 tahun. Sebelum dilaksanakan penelitian dilakukan adanya skrining terlebih dahulu untuk memastikan bahwa responden mengalami disminor primer di setiap bulannya. Pengukuran skala nyeri menggunakan skala nyeri NRS (Numeric rating Scale) Setelahnya, dilakukan pendataan perihal jadwal menstruasi, untuk memastikan tindakan senam aerobic low impact dapat dilakukan dua minggu sebelum menstruasi berlangsung. Analisis data meliputi univariabel yang menyajikan distribusi frekuensi, bivariabel dengan uji wilcoxon.

Pemberian perlakukan senam aerobik Low Impact diberikan selama 4 kali dalam waktu 2 Minggu sebelum periode menstruasi. 


\section{HASIL DAN PEMBAHSAN}

Karakter Subyek Penelitian

Distribusi frekuensi subyek penelitian dapat di lihat pada tabel 1:

Tabel 1. Karakter Subyek Penelitian

\begin{tabular}{|c|c|c|c|}
\hline No & Karakteristik & & Kasus \\
\hline & & $\mathbf{n}$ & $\%$ \\
\hline \multirow[t]{4}{*}{1} & Usia & & \\
\hline & 12 tahun & 3 & 9 \\
\hline & 13 tahun & 13 & 39.4 \\
\hline & 14 tahun & 14 & 49.6 \\
\hline \multirow[t]{4}{*}{2} & Tinggi badan & & \\
\hline & $140-150 \mathrm{~cm}$ & 5 & 20 \\
\hline & $151-160 \mathrm{~cm}$ & 20 & 60 \\
\hline & $161-170 \mathrm{~cm}$ & 5 & 20 \\
\hline \multirow[t]{3}{*}{3} & $\begin{array}{l}\text { Indeks massa } \\
\text { tubuh (IMT) }\end{array}$ & & \\
\hline & Kurus & 10 & 38 \\
\hline & Normal & 20 & 62 \\
\hline \multirow[t]{5}{*}{4} & Usia menarche & & \\
\hline & 12 tahun & 12 & 57.8 \\
\hline & 13 tahun & 13 & 37 \\
\hline & 14 tahun & 3 & 4 \\
\hline & 15 tahun & 2 & 1,2 \\
\hline \multirow[t]{3}{*}{5} & Status Ekonomi & & \\
\hline & Tinggi & 24 & 48 \\
\hline & Rendah & 6 & 52 \\
\hline \multirow[t]{3}{*}{6} & $\begin{array}{l}\text { Jarak tempat } \\
\text { tinggal }\end{array}$ & & \\
\hline & Jauh & 12 & 55 \\
\hline & Dekat & 18 & 45 \\
\hline
\end{tabular}

Karakteristik responden pada penelitian ini, didominasi dengan remaja usia 14 tahun (49\%), demgam mayoritas usia menarche di usia 12 tahun (57.8\%).

Tabel 2. Karakteristik Nyeri Aerobik

\begin{tabular}{lcc}
\hline \multicolumn{1}{c}{ Karakteristik nyeri } & Jumlah & Prosentase \\
\hline $\begin{array}{l}\text { Sebelum aerobic low } \\
\text { impact }\end{array}$ & & \\
Tinggi & 0 & 0 \\
Sedang & 22 & 73,3 \\
Ringan & 8 & 26,7 \\
& 30 & 100 \\
Setelah aerobic low & & \\
impact & & \\
Tinggi & 0 & 0 \\
Sedang & 7 & 26 \\
Ringan & 23 & 74 \\
& 30 & $\mathbf{1 0 0}$ \\
\hline
\end{tabular}

Berdasarkan tabel 2. Didapatkan bahwa mayoritas repsonden mengalami skala nyeri disminor sedang (4-6) pada saat sebelum dilakukan senam aerobic low impact. Sedangkan setelah dilakukan senam aerobic low impact menjelang menstruasi, didapatkan hasil mayoritas responden menyatakan terjadi penurunan nyeri pada skala ringgan (1-3)

Pengaruh Senam Aerobik Low Impac terhadap Nyeri Disminore

Tabel 3. Analisis Wilxocon Pengaruh Senam Aerobik Low Impac terhadap Nyeri Disminore

\begin{tabular}{lc}
\hline & $\begin{array}{c}\text { Pe-post } \\
\text { Kel perlakuan }\end{array}$ \\
\hline Z & $-6,678^{\mathrm{a}}$ \\
Asymp. Sig. (2-tailed) &, 000 \\
\hline
\end{tabular}

Berdasarkan tabel 3 hasil analisa data menggunakan uji wilcoxon menunjukkan nilai $(p=0,000)$ dengan nilai $p<0.05$. Dari hasil tersebut dapat disimpulkan bahwa terdapat pengaruh aerobic low impact terhadap penurunan nyeri pada disminore primer.

Salah satu faktor penting penyebab terjadinya disminore primer pada wanita adalah usia menarche. Usia menarche pada remaja sekarang mengalami perubahan menjadi lebih cepat. Hal ini sejalan dengan penelitian yang dilakukan oleh Savitri dan Citrawathi yang menyatakan bahwa jumlah remaja yang mengalami menarche mengalami peningkatan seiring berkembangnya zaman. Tersedianya menu pilihan makanan siap saji yang menjadi favorit remaja berdampak pada kandungan tinggi lemak pada tubuh. Timbunan lemak yang terjadi dalam waktu yang cukup lama tanpa disertai dengan aktivitas fisik yang memadai mengakibatkan tingginya kadar leptin dalam darah. Leptin sangat berpengaruh terhadap metabolisme sistem syaraf Gonadotropin Releazing Hormone (GnRH). GnRH merupakan hormon yang berpengaruh terhadap kematangan reproduksi, dan selanjutnya akan memicu stimulus Follicle Stimulating Hormone (FSH) dan Luteinizing Hormone (LH) di ovarium sehingga terjadi pematangan folikel dan pembentukan estrogen yang digunakan untuk mengawali pubertas semakin dini Sunarto dan Susanti ${ }^{7}$.

Pubertas dini dengan konsekuensi ketidaksiapan remaja dalam menghadapi menarche secara fisik maupun psikologis menimbulkan permasalahan sendiri pada remaja, yaitu disminore primer. Hal ini sejalan dengan 
penelitian yang dilakukan oleh Fuadah (2016), bahwasanya ketidaksiapan organ-organ reproduksi dan ukuran organ reproduksi (servik) dapat menyebabkan rasa nyeri saat menstruasi. Selain itu, kondisi menarche dini menyebabkan peningkatkan jumlah hormon ekstrogen dibandingkan remaja yang belum menstruasi. ${ }^{8}$ Sehingga, menarche dini memungkinkan terjadinya disminore primer dibandingkan wanita yang menarche di usia yang matang. Hal ini dipertegas dengan penelitian yang dilakukan oleh Sari Dkk yang menyatakan bahwa terdapat hubungan yang signifikan antara umur menarche dengan kejadian dismenorea dengan nilai $p=0,000$. Hasil penelitian menunjukkan umur menarche $<12$ tahun 48 orang $(66,7 \%)$ mengalami kejadian dismenorea, sedangkan 24 orang $(33,3 \%)$ tidak mengalami kejadian dismenorea.

Hasil uji statistic menyatakan bahwa terdapat pengaruh senam aerobic low impact terhadap penurunan nyeri dismenore pada remaja putri di Surakarta dengan $p$ value $(0,000)$. Berdasarkan hasil penelitian, sebelum dilakukan senam aerobic low impact didapatkan mayoritas nyeri yang dialami remaja putri berada pada level nyeri sedang sejumlah $73 \%$, setelah melakukan senam aerobic low impact mayoritas remaja putri di level nyeri ringan (76\%). Hal ini sejalan dengan penelitian yang dilakukan oleh Suwarningsih pada 46 responden dengan menggunakan dsitraksi senam aerobic untuk menurunkan nyeri pada mahasiswa. ${ }^{10}$

Hasil penelitian ini menunjukkan bahwa setelah diberikan perlakuan senam aerobic low impact terdapat penurunan derajat nyeri pada dismenore. Penurunan sakal nyeri disebabkan adanya proses distraksi dan relaksasi yang dilakukan oleh responden melalui senam aerobic low impact. Hal ini sejalan dengan penelitian yang dilakukan oleh Hastuti untuk bahwa aktivitas fisik berupa senam aerobic low impact meningkatkan kebugaran jasmani 20 responden dan dapat menghambat impuls nyeri karena adanya ditraksi atau pengalihan perhatian ${ }^{11}$

Senam aerobic low impact dapat menurunkan nyeri pada disminore primer remaja melalui kadar ßendorphin yang meningkat 4 sampai 5 kali di dalam darah ketika melakukan senam. Kadar $\beta$-endorphin meningkat seiring banyaknya aktifitas fisik dan senam erobik yang kita lakukan. $\beta$-endorphin yang keluar dalam tubuh akan diterima oleh reseptor di dalam hipothalamus dan sistem limbik yang berfungsi untuk mengatur emosi dalam tubuh. Peningkatan $\beta$-endorphin terbukti efektif menurunkan rasa nyeri, meninmgkatkan konsentrasi, meningkatkan nafsu makan, dan menstabilkan status hemodinamik tubuh. Sehingga senam aerobic low impact sangat efektif dalam mengurangi skala nyeri terutama dysmenorrrhea. ${ }^{11}$

Hal ini sesuai dengan penelitian Suparto menunjukkan bahwa senam dysmenorrhea efektif untuk mengurangi disminor pada remaja. Penelitian ini membuktikan bahwa kelompok perlakuan remaja yang melakukan senam aerobic low impact mengalami penurunan skala nyeri daripada kelompok kontrol yang hanya melakukan relaksasi nafas dalam. Hal ini menunjukkan bahawa semakin tinggi kadar $\beta$-endorphin terbukti dapat menurunkan skala nyeri. ${ }^{11}$

\section{SIMPULAN DAN SARAN}

Simpulan dari penelitian ini bahwa Senam aerobic low impact terbukti memiliki pengaruh efektif dalam menurunkan derajat nyeri pada dismenore. Mayoritas responden yang sebelumnya mengalami nyeri sedang, menurun menjadi skla nyeri ringan. Saran yang diberikan berdasarkan penelitian ini yaitu :

1. Hasil penelitian itu bisa dijadikan tambahan informasi oleh remaja terkait intervensi yang dapat dilakukan untuk mengatasi nyeri pada disminore.

2. Hasil penelitian ini dapat digunakan untuk pertimbangan kebijakan khususnya sekolah dalam menyusun program kesehatan reproduksi remaja beserta intervensi kesehatan didalamnya.

3. Diharapkan kepada peneliti selanjutnya untuk dapat melakukan penelitian secara mendalam mengenai intervensi - intervensi lain yang dapat digunakan untuk menurunkan nyeri terutama pada disminore primer remaja.

\section{DAFTAR PUSTAKA}

1. Hickey, V.J. 2013. The Clinical Practice of Neurogical and Neurosurgical Nursing. 4th edition. Philadhelphia : Lippicott Williams and Wilkins

2. Holder, M.D. 2016. Happines in Children : Measurent Corrilates and Enhasment of $e$ Positive Subjectif Well Being. London : Springer.

3. Van Rensburg, K. 2011. Managing dysmenorrhoea in the pharmacy: review. $S A$ Pharmaceutical Journal, 78(1): 42-44.

4. Prawirohardjo, S., Wiknjosastro, H. \& Sumapraja, S. (2018) IImu Kandungan (Edisi Ketiga). Jakarta: Yayasan Bina Pustaka Sarwono, 274-278.

5. Dawood, M. Y. (2016) Primary dysmenorrhea: advances in pathogenesis and management. Obstetrics \& Gynecology, 108(2): 428-441. 
6. French, L. (2015) Dysmenorrhea. American family physician, 71(2): 285-291.

7. Savtri dan Citrawathi. Hubungan Status Gizi Dan Usia Menarche Dengan Kejadian Dismenore Siswi Smp Negeri 2 Sawan. 2019. Jurnal Pendidikan Biologi Undhiksa : Vol 2

8. Fuadah F. 2016. Hubungan antara Status Gizi dengan Usia Menarche pada Remaja Putri diSMP Umi Kulsum Banjaran Kab. Bandung Provinsi Jawa Barat Tahun 2016. J IImuKesehatan.;10(2):707-14

9. Sari, K.S.N., Sumaryani, S., Trisetyaningsih, Y., 2015. Pola Perilaku Remaja untuk Menangani Keluhan Dsymenorrhoea di SMK Muhammadiyah 2 Moyudan Sleman Yogyakarta. Media Ilmu Kesehatan. 4(1): 30-6.

10. Suwarnisih, K.A, \& Anindhita Y.C. 2017. Hubungan usia menarche dengan kejadian dismenore pada remaja putri di SMP N 17 Surakarta.. Jurnal Maternal STIKes Mitra Husada Karanganyar Vol. 2, No. 1.

11. Hastuti, witri dan widyaningsih W. 2020. Senam Aerobic Untuk Mengatasi Nyeri Menstruasi Pada Remaja Putri Di Pondok Pesantren Al Ishlah Semarang. Jurnal Kesehatan Kusuma Husada : Vol 11 no 1

12. Suparto, Achmad. 2011. Efektifitas Senam Dismenore dalam Mengurangi Dismenore pada Remaja Putri. Phederal. Vol 4 No.1. Mei 2011. Hal. 7 